\title{
Síndrome de Burnout na gestão escolar
}

\section{Burnout Syndrome in school management \\ Síndrome de Burnout en la administración escolar}

\author{
Erika Cristina de Carvalho Silva Pereira \\ Universidade Federal do Pará (UFPA), Belém/PA - Brasil \\ Luciana Cristina de Souza \\ Universidade Estadual de Campinas (Unicamp), Campinas/SP - Brasil
}

\section{Resumo}

Este estudo teve como objetivo verificar a prevalência das dimensões da Síndrome de Burnout: exaustão emocional (EE), despersonalização (DE) e realização pessoal no trabalho (RP), de 15 profissionais que atuavam na administração escolar de uma rede de ensino privada, situada na região norte do Brasil. Foi uma pesquisa de campo, de abordagem quantitativa e de cunho exploratório. Utilizou o questionário Maslach Burnout Invetory (MBI), com quatro diretoras, cinco coordenadoras pedagógicas, quatro orientadoras educacionais e duas gestoras com dupla função, de coordenadoras e orientadoras. Os resultados mostraram que a maioria das participantes apresentou alta exaustão emocional, baixa despersonalização e moderado nível de realização pessoal no trabalho, evidenciando que a síndrome pode estar em desenvolvimento no grupo investigado. Conclui-se que é preciso um suporte psicológico para lidar com os sintomas iniciais da síndrome na amostra investigada.

Palavras-chave: Esgotamento profissional, Diretor escolar, Coordenador pedagógico, Orientador educacional

\begin{abstract}
This study's objective was to verify the prevalence of Burnout Syndrome: emotional exhaustion (EE), depersonalization (DE) and personal achievement at work (PA) of 15 professionals working in the private education system's school administration in Northern Region of Brazil. It was a field research, with a quantitative and exploratory approach. It used the Maslach Burnout Invetory (MBI) questionnaire with four directors, five pedagogical coordinators, four educational leaders and two with both function of coordinators and counselors. The results showed that most of the participants had high emotional exhaustion, low depersonalization and moderate level of personal accomplishment at work, showing that the syndrome may be under development in the investigated group. It concludes that psychological support is needed to deal with the initial symptoms of the syndrome in the sample investigated.
\end{abstract}

Keywords: Professional exhaustion, School director, Pedagogical coordinator, Educational advisor

\section{Resumen}

Este estudio tuvo como objetivo verificar la prevalencia de las dimensiones del Síndrome de Burnout: agotamiento emocional (AE), despersonalización (DE) y realización personal en el trabajo (RP), de 15 profesionales que actuaban en la administración escolar de una red de enseñanza privada, ubicada en la Región 
Norte de Brasil. Fue una investigación de campo, de abordaje cuantitativo y de cuño exploratorio. Utilizó el cuestionario Maslach Burnout Invetory (MBI) con cuatro directoras, cinco coordinadoras pedagógicas, cuatro orientadoras educativas y dos que tenían la doble función, de coordinadoras y orientadoras. Los resultados mostraron que la mayoría de los participantes tenían un alto agotamiento emocional, baja despersonalización y un nivel moderado de logro personal en el trabajo, lo que demuestra que el síndrome puede estar desarrollándose en el grupo investigado. Se concluye que es necesario un soporte psicológico para lidiar con los síntomas iniciales del síndrome en la muestra investigada.

Palabras-clave: Agotamiento profesional, Director escolar, Coordinador pedagógico, Orientador educativo

\section{Introdução}

Profissionais da educação estão sempre diante de constantes mudanças no setor, com inúmeras demandas sobrepostas diariamente à escola pela sociedade. São exigências que vão além da relação ensino-aprendizagem, como, por exemplo, as contínuas modificações na legislação educacional brasileira nos últimos anos, a necessidade de buscar e inserir as novas tecnologias de ensino no processo educativo, de cumprir metas e resultados em avaliações de grande escala, de lidar com a nova geração alunos que chegam às instituições, tendem a sobrecarregar tanto física como mentalmente os sujeitos que nela exercem seu trabalho, causando, inclusive, adoecimento.

Entre os problemas de saúde mental relacionados ao trabalho, encontrase a Síndrome de Burnout, que tem sido investigada nas mais diversas áreas de atuação profissional. No Brasil, de acordo com o Ministério da Saúde, também pode ser conhecida como Síndrome de Esgotamento Profissional ou Sensação de Estar Acabado (BRASIL, 2001).

De acordo com Maslach e Jackson (1981), o Burnout é uma síndrome de esgotamento emocional, que acomete com frequência indivíduos que lidam diretamente com o trato de pessoas no ambiente de trabalho, tais como médicos, enfermeiros, psicólogos, bombeiros, professores, entre outros. Pode também ser concebida como uma resposta ao estresse crônico no ambiente laboral. A síndrome é caracterizada pelo desenvolvimento de sintomas que se apresentam em três dimensões básicas: a exaustão emocional [EE], a despersonalização [DE] e a reduzida de realização pessoal no trabalho [RP] (MASLACH; GOLDBERG, 1998; PÊGO; PÊGO, 2015). 
A EE se relaciona ao sentimento de estar emocionalmente sobrecarregado e exausto pelo trabalho, não apenas mentalmente como também fisicamente. A DE está associada a um comportamento insensível e impessoal com os usuários do serviço prestado e com os colegas de trabalho. Já a reduzida RP se associa a sentimentos de insatisfação, de incompetência, desmotivação e baixa autoestima em relação ao trabalho realizado (MASLACH; JACKSON, 1981; PIRES et al, 2012).

Segundo Carlotto (2002) a Síndrome de Burnout é a doença mais frequente entre os profissionais da educação, e, na maioria dos estudos, o professor é o sujeito mais investigado no contexto escolar. Faz-se necessário, portanto, realizar um maior número de pesquisas voltadas também para os demais sujeitos envolvidos nas relações que se dão dentro da escola e que afetam diretamente todo o clima organizacional e a qualidade do ensino oferecida nas instituições de educação básica, tais como gestores, coordenadores e orientadores educacionais.

De acordo com Guimarães (2013) o gestor escolar está exposto a uma diversidade de fatores estressores. Estudos têm constatado a ocorrência de um nível de estresse alto entre esses profissionais, o que tem levado ao desenvolvimento de quadros mais graves como o Burnout, que, nos contextos laborais, tem entre suas características sintomáticas mais evidentes, a apatia, o desestímulo e o descuido do profissional para com o desenvolvimento de suas tarefas, além da apresentação de mal-estar físico ou mental (GUIMARÃES, 2013).

Mazon e Leite (2013) realizaram um estudo que teve como objetivo identificar e analisar o impacto de eventos estressores em gestores escolares. Participaram da pesquisa 29 gestoras que atuavam na função de diretoras ou vice-diretoras, no município de São Paulo. Elas responderam ao Inventário Impil (Evaluación Psicológica Del Estrés por Inestabilidad Laboral). Os resultados desse estudo indicaram que as transformações sociais aceleradas, as exigências das reformas educacionais e a falta de reconhecimento da profissão foram associadas ao mal-estar docente das gestoras. Além disso, as entrevistadas apresentaram maiores pontuações em estressores relacionados à preocupação com a saúde, preocupações econômicas e moléstias emocionais (MAZON; LEITE, 2013). 
Na região norte do Brasil, Melo (2015) buscou compreender o trabalho dos gestores do ensino médio da rede pública de ensino e os efeitos subjetivos em sua saúde mental. Sete gestores, do município de Rio Branco, no Acre, participaram da pesquisa. A autora concluiu que a atividade dos gestores escolares apresenta uma sobrecarga de trabalho, uma vez que eles têm que lidar com uma complexidade de questões presentes nas escolas.

Diante da realidade apresentada na literatura, percebe-se que os gestores escolares, coordenadores e orientadores educacionais precisam ser investigados quanto à saúde emocional, uma vez que estão diante de inúmeras demandas e complexidades inerentes à dinâmica do trabalho na escola.

Além disso, constata-se, a partir das buscas para construção de uma fundamentação teórica para este estudo, que há uma carência de pesquisas que analisem a saúde mental da equipe de gestão escolar. Não foram encontrados estudos sobre Síndrome de Burnout nesses profissionais. Ainda é importante destacar que a produção acadêmica encontrada está centrada nos sujeitos que atuam nas escolas públicas, sendo escassas as pesquisas realizadas na rede privada de ensino.

Sendo assim, este estudo pretende contribuir, ao apresentar dados referentes às dimensões do Burnout nesse grupo profissional de grande relevância para que a escola funcione, de modo a alcançar os objetivos voltados à formação humana e qualidade educacional para todos os sujeitos que nela se desenvolvem. Os dados levantados também podem auxiliar a averiguar a relação entre as características do trabalho e o desenvolvimento da síndrome.

Objetivou-se, portanto, verificar a prevalência das dimensões da Síndrome de Burnout - exaustão emocional, despersonalização e realização pessoal no trabalho - na equipe administrativa escolar, a saber, gestores, coordenadores e orientadores escolares de uma rede privada de ensino. Além disso, buscou-se identificar as principais fontes de sentimentos negativos em relação ao trabalho dos administradores escolares e estabelecer relações entre as dimensões da síndrome com as variáveis sociodemográficas e de trabalho. 


\section{Material e métodos}

Este estudo consiste numa pesquisa de campo, de abordagem quantitativa e de cunho exploratório. Ela foi realizada em uma rede privada de ensino da educação básica, com sede em Belém, no estado do Pará, mas que atinge também a região metropolitana do município e possui uma unidade escolar na cidade de Macapá, estado do Amapá. A instituição conta no total com seis diretores escolares, oito coordenadoras pedagógicas, nove orientadoras educacionais e duas pedagogas que atuam na dupla função de coordenação e orientação, um total de 25 profissionais ligados à gestão escolar dessa rede de ensino.

Primeiramente, contatou-se a administração geral das escolas, a fim de explicar a finalidade da pesquisa e solicitar autorização para realizá-la com a equipe administrativa das unidades de ensino. Em seguida, após a aprovação para aplicação do estudo, foi elaborado um formulário on-line e encaminhado por meio eletrônico, através de aplicativo de mensagens de texto, o Termo de Consentimento Livre e Esclarecido (TCLE), juntamente com os instrumentos de coleta, para que a coordenação geral da instituição repassasse à equipe de gestores(as), coordenadores(as) e orientadores(as) educacionais.

As participantes responderam aos questionários acessando um link de URL, que, uma vez preenchidos completamente, eram armazenados em planilha de Excel, de acesso exclusivo dos pesquisadores. Sendo assim, ainda que os instrumentos on-line tenham sido repassados aos profissionais por meio da administração geral da rede de ensino, apenas os pesquisadores tiveram acesso a esses formulários preenchidos, garantindo o sigilo das respostas dadas. Além disso, manteve-se o anonimato no preenchimento, visto que não era solicitado que as participantes se identificassem. Cabe esclarecer ainda, que as participantes foram informadas dos objetivos e cuidados éticos e consentiram em assinalar afirmativamente o TCLE.

A amostra foi do tipo não probabilística, constituída pelas profissionais que aceitaram participar da pesquisa, sendo quatro diretoras $(n=4)$, cinco coordenadoras pedagógicas $(n=5)$, quatro orientadoras educacionais $(n=4)$ e mais duas professoras que atuavam na coordenação e orientação escolar concomitantemente $(n=2)$, totalizando o número de 15 participantes $(n=15)$. 
Como instrumento para coleta de dados, utilizou-se o questionário Maslach Burnout Invetory (MBI), adaptado para professores, uma vez que todos as participantes são profissionais da educação, com formação inicial na docência, e pretendia-se avaliá-las como sujeitos que trabalham na área educacional, assim como aplicado por Codo (1999). O MBI é um instrumento mundialmente reconhecido para mensurar e identificar o Burnout e suas dimensões e foi desenvolvido por Maslash e Jackson (1981). Esse inventário possui adaptações e traduções para o Brasil, além de já ter sido utilizado em diversos estudos com professores (SINOTT, 2013; PIRES et al, 2012; CODO, 1999).

O MBI é um questionário com escala do tipo Likert, de sete pontos, que permite verificar o grau de concordância do entrevistado diante das afirmativas feitas. As variáveis indicam a frequência com que ocorre diante de determinado sentimento em relação ao trabalho. A descrição de cada ponto na escala é: 0 Nunca; 1 - Uma vez ao ano; 2 - Uma vez ao mês; 3 - Algumas vezes ao mês; 4 - Uma vez por semana; 5 - Algumas vezes por semana; 6 - Todos os dias.

A versão do $\mathrm{MBI}$ utilizada, conta com 22 questões afirmativas, que buscam avaliar a exaustão emocional, a despersonalização e a realização pessoal no trabalho (BENEVIDES-PEREIRA, 2001). É importante destacar que foi realizada uma customização nos termos para a equipe de gestão escolar, incluindo "professores", "pais", "funcionários" em algumas questões, uma vez que esses profissionais não lidam apenas com os alunos.

As respostas numéricas de cada dimensão foram analisadas de acordo com a classificação de Benevides-Pereira (2001) em baixo, médio e alto nível, como se verifica na Tabela 1. A dimensão EE possui nove itens na escala (questões 1, 2, 3, 6, 8, 13, 14, 16 e 20), a DE, cinco itens (questões 5,10,11, 15 e 22) e a RP no trabalho conta com oito itens no inventário (questões 4, 7, 9, 12, $17,18,19$ e 21).

Tabela 1: Pontos de corte para classificação das dimensões do Burnout

\begin{tabular}{lccc} 
Dimensões da Síndrome de Burnout & \multicolumn{3}{c}{ Pontos de Corte } \\
\cline { 2 - 4 } & BAIXO & MÉDIO & ALTO \\
\hline Exaustão Emocional & $0-15$ & $16-25$ & $26-54$ \\
\hline Despersonalização & $0-02$ & $03-08$ & $09-30$ \\
\hline Realização Pessoal & $0-33$ & $34-42$ & $43-48$
\end{tabular}

Fonte: Sinott (2013); Benevides-Pereira (2001)

Revista Educação Online, Rio de Janeiro, n. 32, set-dez 2019, p. 180-205 
Nas dimensões EE e DE, quanto maiores os índices, maior será o nível de Burnout. Já em relação à reduzida RP no trabalho, quanto menor a pontuação, maior é o nível da síndrome.

Além do $\mathrm{MBI}$, foi aplicado um questionário de caracterização do participante, com questões referentes aos fatores sociodemográficos (sexo, idade, estado civil, formação) e relacionados ao trabalho (tempo de exercício na função, carga horária de trabalho, fontes de sentimentos negativos em relação ao trabalho). Os dados foram armazenados em planilha do Excel, versão 2010. Para análise das dimensões do Burnout e das características sociodemográficas, foi utilizada estatística descritiva, a partir dos cálculos das médias encontradas, além dos valores absolutos. Os questionários foram aplicados no mês de setembro de 2018.

\section{Resultados e discussão}

\subsection{Característica de trabalho dos gestores, coordenadores pedagógicos e orientadores educacionais}

Antes de tudo, é preciso discorrer brevemente sobre as particularidades essenciais que delineiam o trabalho da equipe de gestão, da qual fazem parte o diretor escolar, o coordenador pedagógico e o orientador educacional, uma vez que situações adversas decorrentes dessas características, quando não enfrentadas adequadamente, podem induzir o desencadeamento da síndrome de Burnout nesses profissionais.

Como já se sabe, as imposições diariamente atribuídas aos responsáveis pela liderança escolar são cada vez maiores e mais complexas. As transformações ocorridas no cenário educacional ao longo das últimas décadas trouxeram consigo uma maior diversidade entre as necessidades educacionais dos alunos, maior heterogeneidade e consequentemente mais conflitos, mais professores, mais tarefas burocráticas, implicando em maiores dificuldades de gestão para os administradores e mais tensão entre os envolvidos nas relações escolares.

No caso do diretor escolar, Luck (2009) afirma que essa função está relacionada à liderança e organização do trabalho de todos os que atuam na escola, de maneira a conduzi-los no desenvolvimento de um espaço educacional 
apto a possibilitar a aprendizagem e a formação dos alunos, de modo que estejam preparados para enfrentar os desafios constantes que são apresentados. Segundo a autora, o diretor é responsável pela organização e orientação tanto administrativa quanto pedagógica da escola.

De acordo com Melo (2015), cabe ao diretor, entre outras tarefas, administrar leis e normas, cuidar do espaço físico da escola, proporcionando estrutura adequada para a aprendizagem dos alunos, cuidar dos recursos financeiros, principalmente nas escolas públicas, de questões legais com os órgãos oficiais de educação, da qualidade do ensino, realizando reuniões periódicas com a coordenação pedagógica, a fim de acompanhar 0 desenvolvimento dos professores e alunos, realizar com regularidade reunião com os pais, lidar com questões referentes a relações interpessoais com funcionários, professores, alunos e as famílias. É indispensável que o diretor escolar se preocupe não apenas com os problemas de cunho burocrático, mas, sobretudo, com a parte pedagógica.

Essas e outras demandas podem acarretar um custo psíquico na prática profissional desses educadores, contribuindo para um sentimento de que nem sempre estão à altura de tais exigências, causando um sentimento de frustração, desânimo e até mesmo o abandono da profissão, que é o estágio final do Burnout em alguns casos. Essas circunstâncias têm efeitos significativos e negativos, não apenas para a vida e saúde do gestor, como também para toda a organização escolar.

Quanto ao coordenador pedagógico, Barros e Eugênio (2014) apontam que sua função primordial é a de formar os docentes da instituição em que atuam, ou seja, é essencialmente a formação continuada em serviço. Além disso, os coordenadores devem trabalhar em parceria com a direção escolar, a fim de que todos busquem, juntos, alternativas que objetivem a aprendizagem dos alunos.

Entretanto, Placco e Almeida (2008), ao investigarem as atividades diárias de dez coordenadores pedagógicos de escolas públicas de São Paulo, identificaram que eles desenvolvem inúmeras tarefas, havendo uma indefinição de suas funções e, consequentemente, uma perda da identidade profissional. Os entrevistados listaram entre suas atividades: organização e execução dos horários de aula, relações formais e informais com a direção escolar, 
professores, alunos, pais e órgãos superiores, comunicados referentes às atividades que envolvem professores e alunos, elaboração de relatórios, questões sobre avaliação, currículo e dinâmica das aulas, decisões sobre atividades extraclasse, resolver conflitos entre professores e alunos, análise de casos disciplinares, contatar pais para resolver situações mais graves, preparação de material a ser utilizado pelo professor, programação de datas comemorativas e eventos, entre outras.

Já no que concerne ao orientador educacional, Pase Neto e Santos (2015) afirmam que ele é o profissional responsável por auxiliar os docentes no desenvolvimento educacional dos educandos. Segundo os autores, por muito tempo, a imagem do orientador educacional esteve associada ao atendimento dos "alunos problemas". Hoje, no entanto, não é mais assim, visto que as áreas de atuação desse profissional se ampliaram, e eles não atuam apenas com os educandos, mas com a comunidade escolar de modo geral.

Além disso, o orientador educacional auxilia a instituição escolar na organização e criação de propostas pedagógicas e no planejamento, de modo que atendam às necessidades dos alunos em suas solicitações e expectativas. Entre seus desafios, estão: intermediar conflitos escolares, auxiliar professores em relação às dificuldades e aprendizagem dos alunos, encaminhar casos específicos de alunos para outros profissionais, auxiliar os discentes no processo de sua aprendizagem e orientá-los em temáticas sociais e afetivas, estabelecer relações de diálogo com as famílias, a fim de que o espaço escolar favoreça o educando, conhecer a realidade a qual os alunos pertencem e verificar quais situações facilitam ou dificultam a vida dos discentes (PASE NETO; SANTOS, 2015).

Percebe-se, portanto, que o trabalho da equipe de gestão escolar perpassa atividades de natureza distintas, desde os aspectos mais burocráticos, relacionados às questões legais e documentais, até a responsabilidade quanto à estrutura escolar e ao fornecimento de condições adequadas para o bom trabalho dos professores e aprendizagem dos alunos, mas, principalmente, as relações interpessoais diretas e indiretas com todos os envolvidos na comunidade escolar que exigem que esses profissionais deem conta de inúmeras expectativas direcionadas à escola. Essas cobranças, quando não 
acompanhadas de condições adequadas de trabalho e suporte organizacional, podem contribuir para o desgaste mental e 0 adoecimento desses educadores.

\subsection{Caracterização da amostra}

Destaca-se inicialmente que 100\% ( $n=15)$ dos participantes são do sexo feminino, o que é um retrato empírico da realidade educacional brasileira. De acordo Oliveira e Viera (2012), a pesquisa sobre Trabalho Docente na Educação Básica no Brasil (Tdebb) realizada pelo Grupo de Estudos sobre Política Educacional e Trabalho Docente (Gestrado), com 8.230 participantes em sete estados brasileiros, constatou que mais de $80 \%$ dos docentes da educação básica brasileira se constitui majoritariamente de mulheres. Em relação ao estado civil, 12 participantes declararam ser casadas, duas são solteiras e uma $(n=1)$ pessoa marcou a opção "outros".

A idade das participantes variou de 25 a 53 anos, sendo a média de idade da amostra geral de $\pm 39,4$ anos. Entre as diretoras, a idade variou de 33 a 48 anos, com média de $\pm 39,2$ anos. Nas que atuam apenas na coordenação pedagógica, a média foi de $\pm 43,2$ anos, variando de 28 a 53 anos. Nas orientadoras educacionais, a média foi de $\pm 41,2$, variando de 31 a 48 . Já nas que exerciam a dupla função, de orientadoras e coordenadoras, a idade média foi 27 anos.

No que diz respeito ao tempo em que exerce a função, houve uma diferença significativa nos dados gerais da amostra, que variou de um mês até 16 anos. Duas ( $n=2)$ atuam há menos de um ano na função, sete $(n=7)$ exercem o cargo de 1 a 5 anos, quatro $(n=4)$ trabalham entre 6 e 10 anos e duas $(n=2)$ já atuam há mais de 10 anos. Na Figura 1, está disposto o tempo de serviço por função. 
Figura 1: Tempo de atuação por função

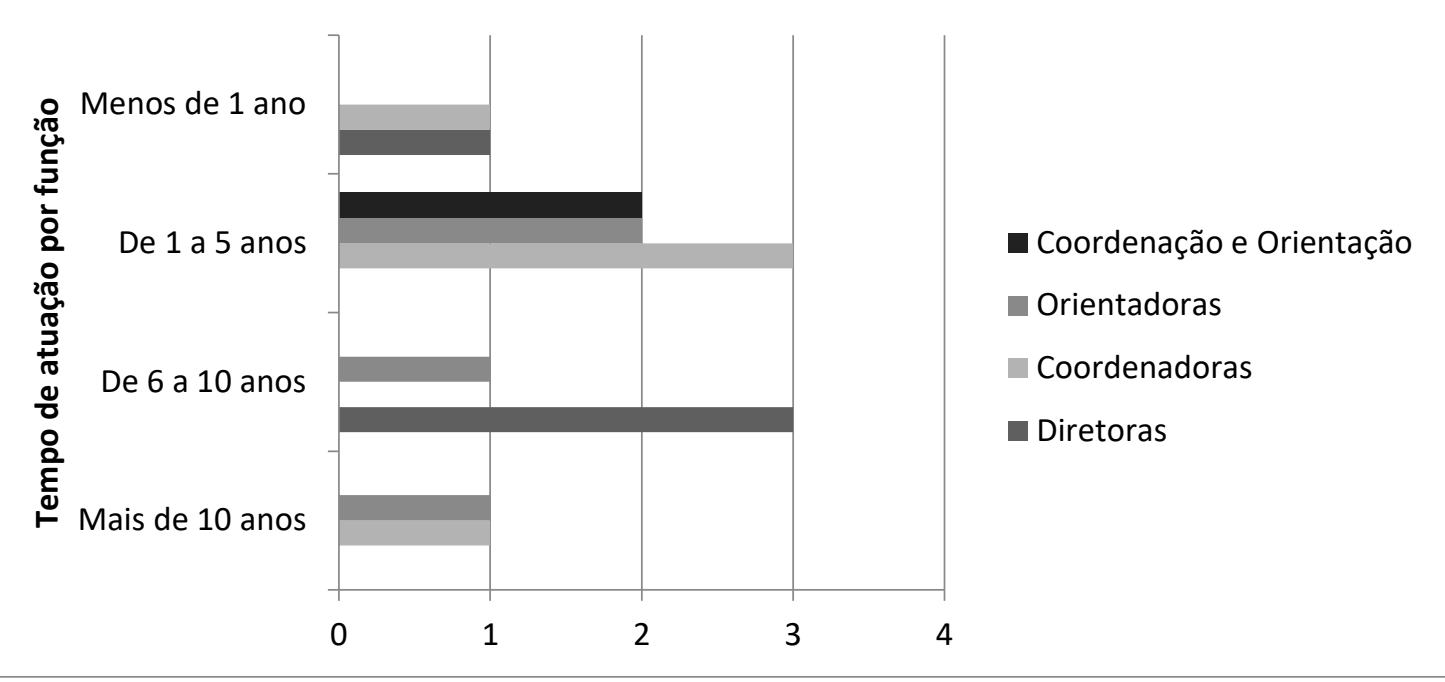

Fonte: Resultados originais da pesquisa

Quanto à formação inicial, $100 \%$ das entrevistadas possuem licenciatura em pedagogia e, dessas, treze ( $n=13)$ declararam possuir pós-graduação, sendo que a maioria dos cursos tem relação com gestão escolar. Apenas duas $(n=2)$ não possuíam pós-graduação até o período em que a pesquisa foi realizada.

Ressalta-se que as escolas em que essas profissionais atuam possuem em média 511,6 alunos, sendo que a escola com o menor número de alunos tem 180, e a maior possui 720 alunos. A rede de ensino participante deste estudo oferece desde a educação infantil ao ensino médio. Essa oferta varia em cada unidade escolar, pois nem todas possuem o ensino médio, por exemplo. Geralmente, as com maior número de alunos são as que têm todos os níveis da educação básica.

Com relação à carga horária de trabalho da amostra geral, onze $(n=11)$ entrevistadas trabalham mais de 40 horas semanais, cinco $(n=5)$, de 30 a 40 horas por semana, uma $(n=1)$ atua de 20 a 30 horas. Além disso, cinco $(n=5)$ atuam nos três níveis de ensino da educação básica, ou seja, educação infantil, ensino fundamental e ensino médio. Outras quatro $(n=4)$ trabalham no ensino fundamental e ensino médio, uma $(n=1)$, apenas no ensino fundamental e a maior parte $(n=6)$ lida com a educação infantil e o ensino fundamental.

\subsection{Dimensões do Burnout na equipe de gestão escolar}

Foram tomados como base os critérios de classificação do $\mathrm{MBI}$, definidos nos estudos originais de Maslach e Jackson (1981) e adaptados e traduzidos 
para o Brasil pelo grupo de estudos coordenado pela professora BenevidesPereira (2001). Nesse sentido, este estudo considera os movimentos iniciais e os já estabelecidos da síndrome, expostos através das dimensões EE, DE e RP, uma vez que podem se instalar de forma silenciosa e progressiva, causando uma sensação de contínuo mal-estar atribuído ao trabalho, porém, sem que o indivíduo se dê conta de que está adoecendo (GARCIA; BENEVIDES-PEREIRA, 2003).

Além disso, Codo e Vasques-Menezes (1999) afirmam que cada uma das dimensões do Burnout deve ser analisada separadamente como uma variável contínua, com níveis baixos, médio e alto. É pela associação do nível de cada uma das três dimensões que se obtém nível do Burnout do sujeito. Ainda segundo os mesmos autores, é importante observar que um índice moderado de Burnout é preocupante do ponto de vista epidemiológico, uma vez que o processo de desenvolvimento da síndrome já se encontra em curso (CODO; VASQUES-MENEZES, 1999).

Partindo dessa premissa, os resultados obtidos nesta análise indicam um possível princípio de Burnout na amostra geral das participantes, visto que os índices de todas as dimensões características da síndrome se encontram em níveis médios, quais sejam: $E E=23,53$ pontos; $D E=3,93$ pontos e $R P=41,83$ pontos. É possível observar também que a pontuação média para EE da amostra total se aproxima consideravelmente da classificação de alto risco para o desenvolvimento do Burnout.

Tratando especificamente de cada dimensão, a Figura 2, expressa os dados referentes a EE na amostra geral, revelando que cinco $(n=5)$ participantes possuem baixos índices. Apesar disso, seis $(n=6)$ apresentam altos índices que, se somados com os níveis médios, pode-se inferir que quase $70 \%$ da equipe administrativa da escola estão exaustas emocionalmente. Comparando com o estudo de Codo (1999), que analisou o Burnout em quase 39 mil trabalhadores da educação, em 1440 escolas no Brasil, entre eles, os diretores, orientadores e supervisores escolares, pode-se observar que houve um aumento considerável nos níveis de EE. O autor encontrou no estado do Pará um índice de 17,2\% de participantes com alta EE. A EE é caracterizada por uma situação em que os trabalhadores sentem que não podem dar mais de si mesmos no nível afetivo. $A$ 
sua energia e os recursos emocionais pessoais parecem ter se esgotado, devido ao contato diário com os fatores estressores (CODO, 1999).

Figura 2: Exaustão emocional na amostra geral da pesquisa

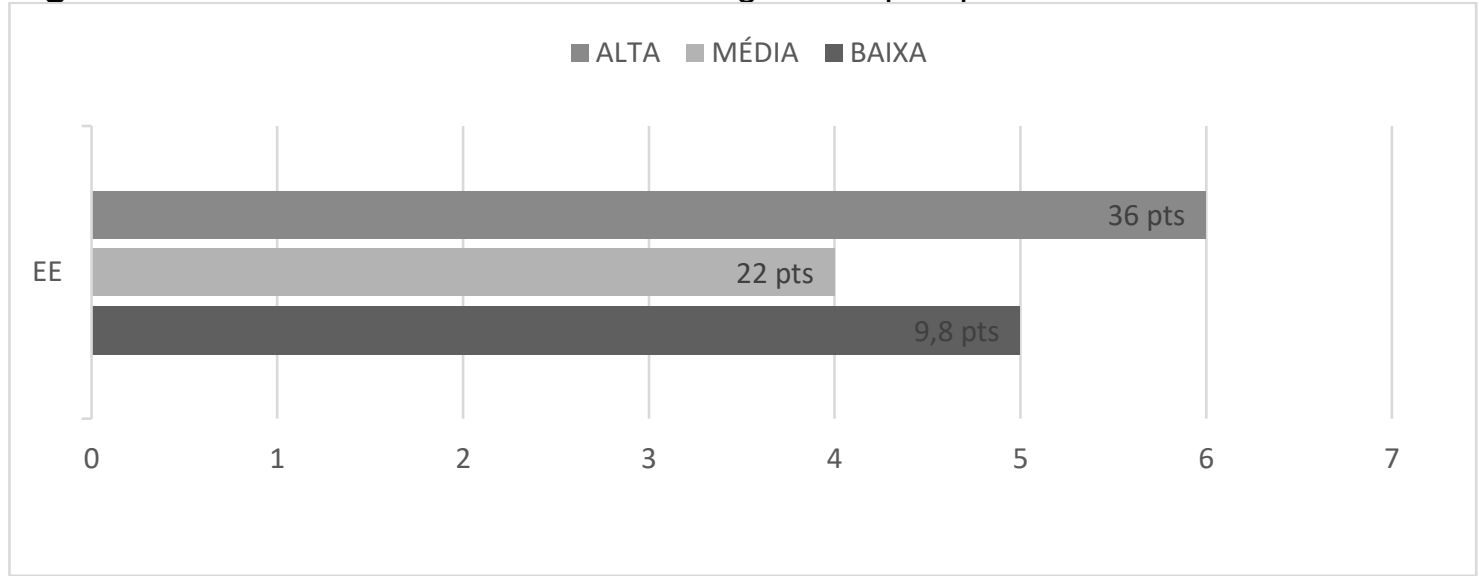

Fonte: Resultados originais da pesquisa

Na Figura 3, são apresentados os dados referentes a EE por função na escola. Percebe-se que duas diretoras $(n=2)$, duas orientadoras $(n=2)$ e duas $(n=2)$ das coordenadoras apresentam altos índices de exaustão. Entre as que atuam na coordenação e orientação ao mesmo tempo, metade teve baixo índice $(n=1)$ e a outra metade, nível médio $(n=1)$. Esses dados podem estar relacionados às inúmeras demandas exigidas por cada função diariamente, uma vez que, de acordo com as questões propostas, sete $(n=7)$ entrevistadas afirmaram sentir-se esgotadas emocionalmente pelo trabalho algumas vezes por mês; sete $(n=7)$ se sentem exaustas algumas vezes por semana, outras cinco $(n=5)$ já começam o dia de trabalho se sentindo cansadas pelo menos algumas vezes por mês.

Figura 3: Exaustão Emocional por função

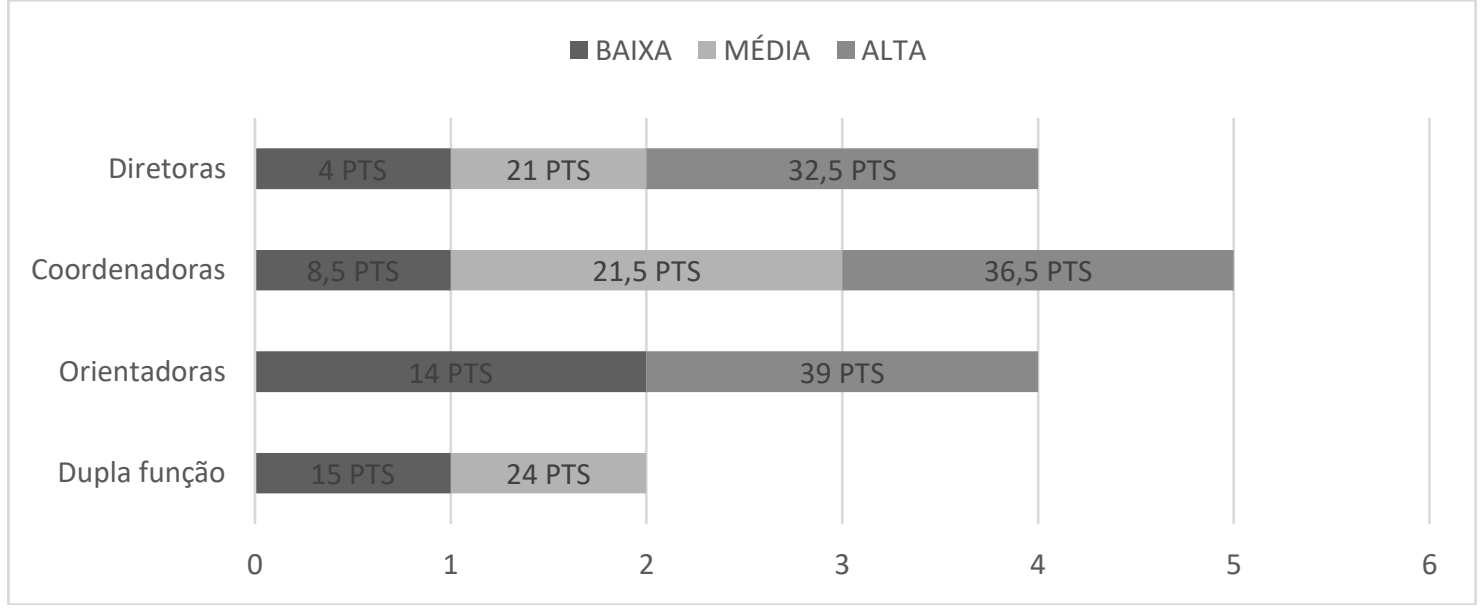

Fonte: Resultados originais da pesquisa 
Os resultados encontrados na EE desta análise corroboram os dados encontrados por Codo (1999), que encontrou $21,7 \%$ de EE entre os diretores escolares e $23,3 \%$ entre os orientadores, realçando que a síndrome está presente em todos os cargos da escola. O autor não utiliza o termo coordenador pedagógico, porém, entre os supervisores de ensino mencionados na pesquisa, Codo (1999) aponta índices de 21,6\% de alta EE.

Outros fatores também devem ser averiguados, pois podem contribuir para o aumento desse esgotamento, como, por exemplo, o estilo de vida, problemas pessoais e as demandas domésticas, que, muitas vezes, se tornam uma segunda jornada de trabalho para mulheres que já atuam fora de casa, sobrecarregando ainda mais seu desgaste físico e mental. Contudo, são questões que precisam ser investigadas em outros estudos.

Além disso, de acordo com Maslach et al (2001), o esgotamento não é algo simplesmente experimentado, ele estimula as ações subsequentes como uma estratégia de defesa do sujeito, que pode distanciar-se emocional e cognitivamente do trabalho, mesmo estando na função, como uma maneira de lidar com a sobrecarga. Esse distanciamento está estritamente relacionado à dimensão da despersonalização.

A despersonalização é uma tentativa de colocar distância entre si e os usuários dos serviços, que, no caso da escola, são os alunos e, por consequência, os seus responsáveis. A tensão constante na relação com os esses usuários pode contribuir para o desenvolvimento do Burnout. Quanto a isso, a maioria das entrevistadas apresentou baixos índices $(n=8)$, o que indica que a equipe de gestão ainda mantém relativamente boas relações interpessoais no ambiente escolar. Porém, observa-se que quatro $(n=4)$ estão com níveis médios e três $(n=3)$ já desenvolveram índices elevados da dimensão como expressa a Figura 4. Esses dados parecem estar ligados a uma atribuição de culpa sobre essas profissionais. Ao responder a afirmativa "Sinto que os alunos/pais/professores/funcionários me culpam por alguns de seus problemas", $46,6 \%$ das participantes assinalaram que isso ocorre de uma vez ao mês até algumas vezes por semana, sendo essa a maior média de pontuação nas questões relacionadas à dimensão da despersonalização. 
Figura 4: Índices de Despersonalização na amostra geral

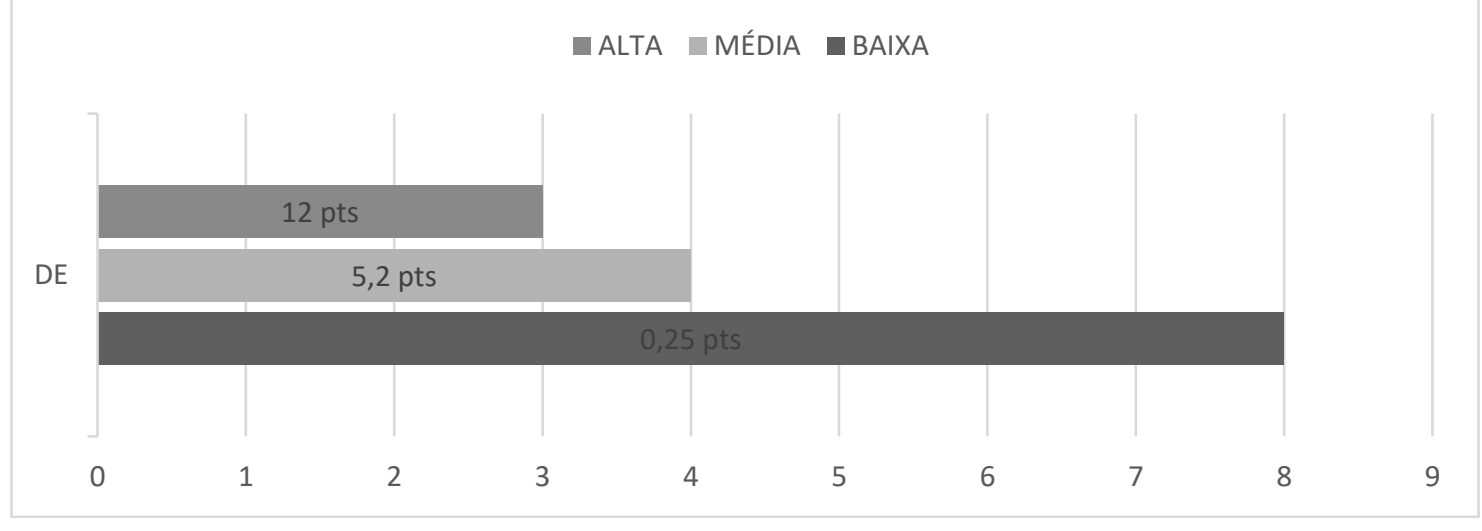

Fonte: Resultados originais da pesquisa

A Figura 5 apresenta os índices de DE, de acordo com a função. Diretoras e coordenadoras são as que manifestaram os índices mais elevados dessa dimensão, apontando a necessidade de medidas interventivas e preventivas, para que o quadro não se agrave. No estudo de Codo (1999), os diretores também apresentaram os maiores índices de DE, correspondendo a 8,3\% da amostra, enquanto nos orientadores educacionais e supervisores de ensino os índices de DE foram de 6,6\% e 6,5\% da amostra geral, respectivamente.

Figura 5: Índices de Despersonalização por função

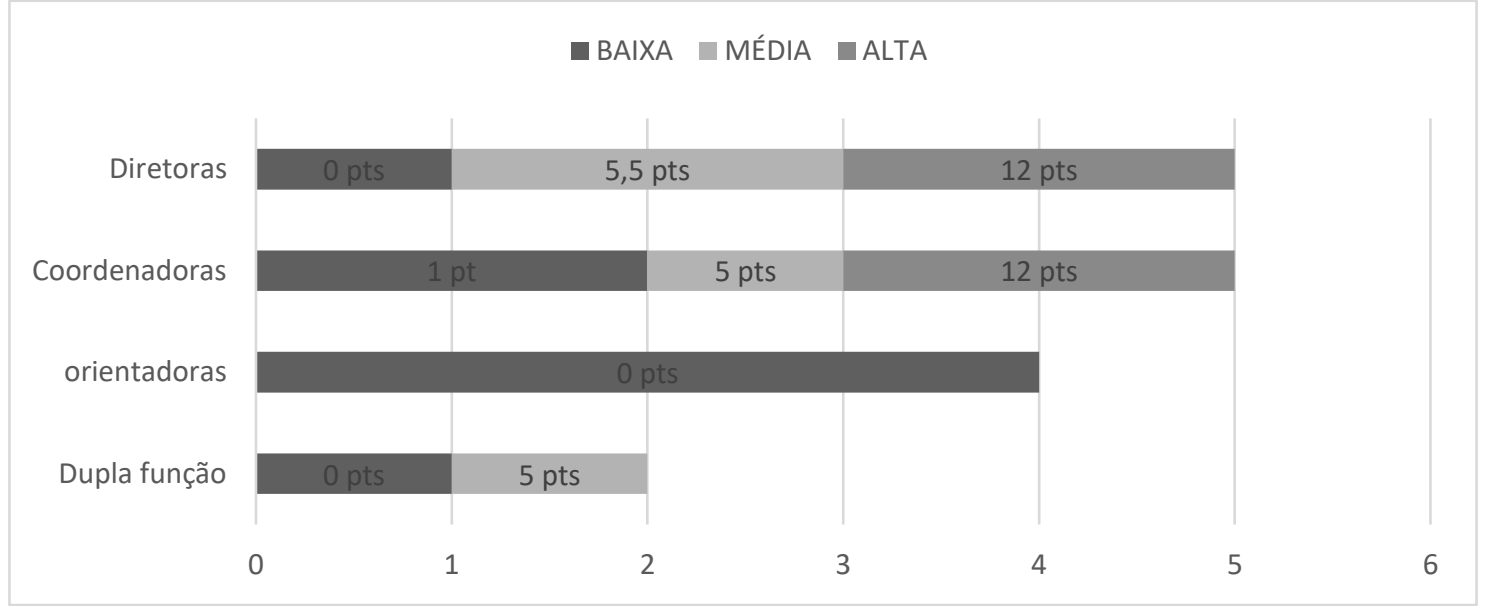

Fonte: Resultados originais da pesquisa

Segundo Benevides-Pereira et al. (2008), na DE, o docente passa a se relacionar de forma impessoal e distante dos alunos, pais e até mesmo dos colegas de trabalho. Apesar disso, é interessante observar que as orientadoras educacionais e as que exerciam dupla função não tiveram representatividade na classificação alta para o desenvolvimento da síndrome. 
Entretanto, nove $(n=9)$ apresentam alta RP em relação ao trabalho, enquanto apenas uma $(n=1)$ teve uma reduzida realização. Conforme Benevides-Pereira et al. (2008), a reduzida RP no trabalho faz com que os sujeitos evidenciem uma insatisfação com a docência, desmotivação, sentimento de ineficácia e baixa autoestima. Há até a possibilidade de pensar em mudar de emprego, ou mesmo de tipo de atividade. Para Codo (1999), o fato de não conseguir alcançar os objetivos aos quais se propõe traz ao docente um sentimento de impotência e de incapacidade. Essa questão tem como tendência fazer com que o profissional avalie a si mesmo negativamente, particularmente com respeito ao próprio trabalho. Porém, o que se observa neste estudo é que apesar das participantes terem apresentado altos índices de EE e indícios de DE, a RP no trabalho ainda não foi totalmente afetada (Figura 6).

Figura 6: Índices de Realização Pessoal na amostra geral

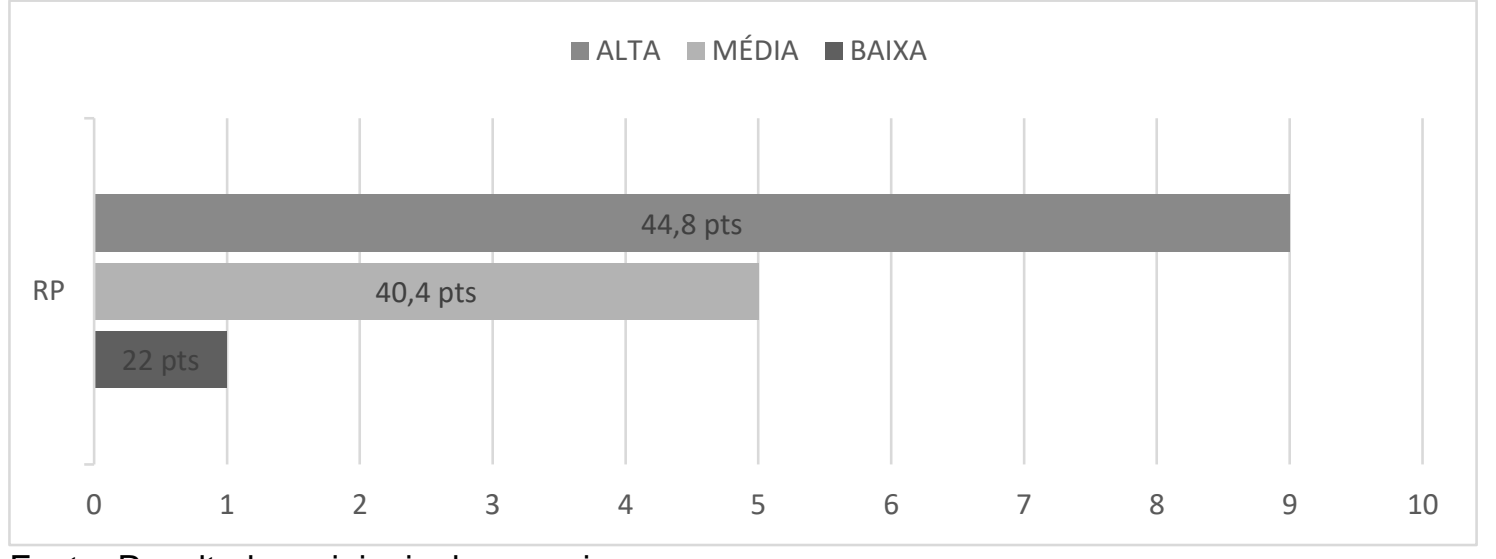

Fonte: Resultados originais da pesquisa

Em se tratando da RP por função, apenas a coordenação pedagógica apresentou classificação de reduzida como expresso na figura 7. Além disso, é importante notar que, entre as que atuam como orientadoras educacionais e as que exercem a dupla função, de orientadoras e coordenadoras, a RP foi de 100\% das participantes. Já entre as diretoras, duas $(n=2)$ apresentaram índices médios e as outras duas ( $n=2)$, altos índices de RP. 
Figura 7: Índices de realização pessoal por função

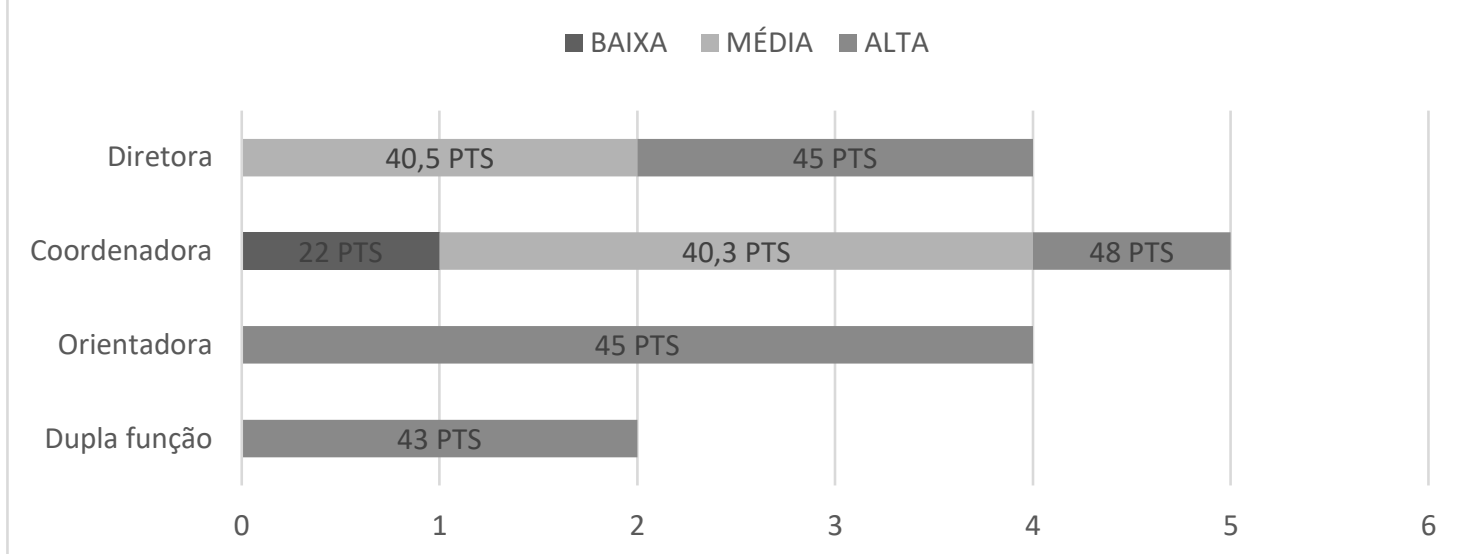

Fonte: Resultados originais da pesquisa

O fato de haver um alto índice de RP pode estar relacionado com o que Robalino (2012) denomina de "polo positivo do trabalho", que seriam manifestações positivas nas pessoas que trabalham, como, por exemplo, o desenvolvimento das capacidades físicas, intelectuais e emotivas que surgem ao realizar alguma atividade laboral e se especializar em determinado meio de trabalho. De acordo com a autora, até mesmo o fato de estar trabalhando, "em épocas de desemprego e subemprego, na população economicamente ativa, ganha mais valor o sentido de polo positivo do trabalho para a saúde e a vida das pessoas" (ROBALINO, 2012), podendo gerar um senso de pertencimento, além de permitir que o trabalhador obtenha bens e serviços para si mesmo e sua família.

A alta realização pessoal, neste estudo, também pode estar atrelada ao sentimento de satisfação com a resolução de problemas relacionados ao trabalho, ainda que as participantes estejam exaustas emocionalmente. Exemplo disso é que questões do $\mathrm{MBI}$, como "Posso entender com facilidade o que sentem os alunos, pais ou professores"; "Lido de forma eficaz com os problemas dos pais, alunos, professores e/ou funcionários"; e "Sinto que influencio positivamente a vida de outros através do meu trabalho" apresentaram as maiores médias de pontos das participantes deste estudo. Entretanto, faz-se necessário que outras investigações sejam feitas, a fim de comparar os resultados no que tange a realização pessoal no trabalho da gestão escolar nas escolas, até mesmo para que seja verificado se existe algum receio ou não dos profissionais em expressar qual o sentimento que experimenta quanto a essa dimensão do Burnout. 


\subsection{Dimensões do Burnout e características sociodemográficas e do trabalho}

As variáveis sociodemográficas relacionadas às dimensões do Burnout foram: estado civil e idade. A categoria sexo não foi avaliada, por não haver parâmetro de comparação, uma vez que todas as participantes do estudo são mulheres. Com relação às características do trabalho, as variáveis analisadas foram o tempo em que exerce a função na escola, a carga horária semanal de trabalho e o nível de ensino em que atua.

No quesito estado civil, as participantes casadas, que representam $80 \%$ da amostra, possuem menores índices de EE e DE e maior RP no trabalho. De modo contrário, as duas ( $n=2)$ participantes solteiras apresentaram alta EE e DE e uma delas $(n=1)$ reduzida RP, sinalizando a presença da síndrome, como mostra a Figura 8. Esses achados podem ser comparados ao estudo de Silva (2014), no qual a autora encontrou altos índices de Burnout, primeiramente nos professores solteiros, ficando os casados em segundo lugar.

Figura 8: Variável estado civil e dimensões do Burnout

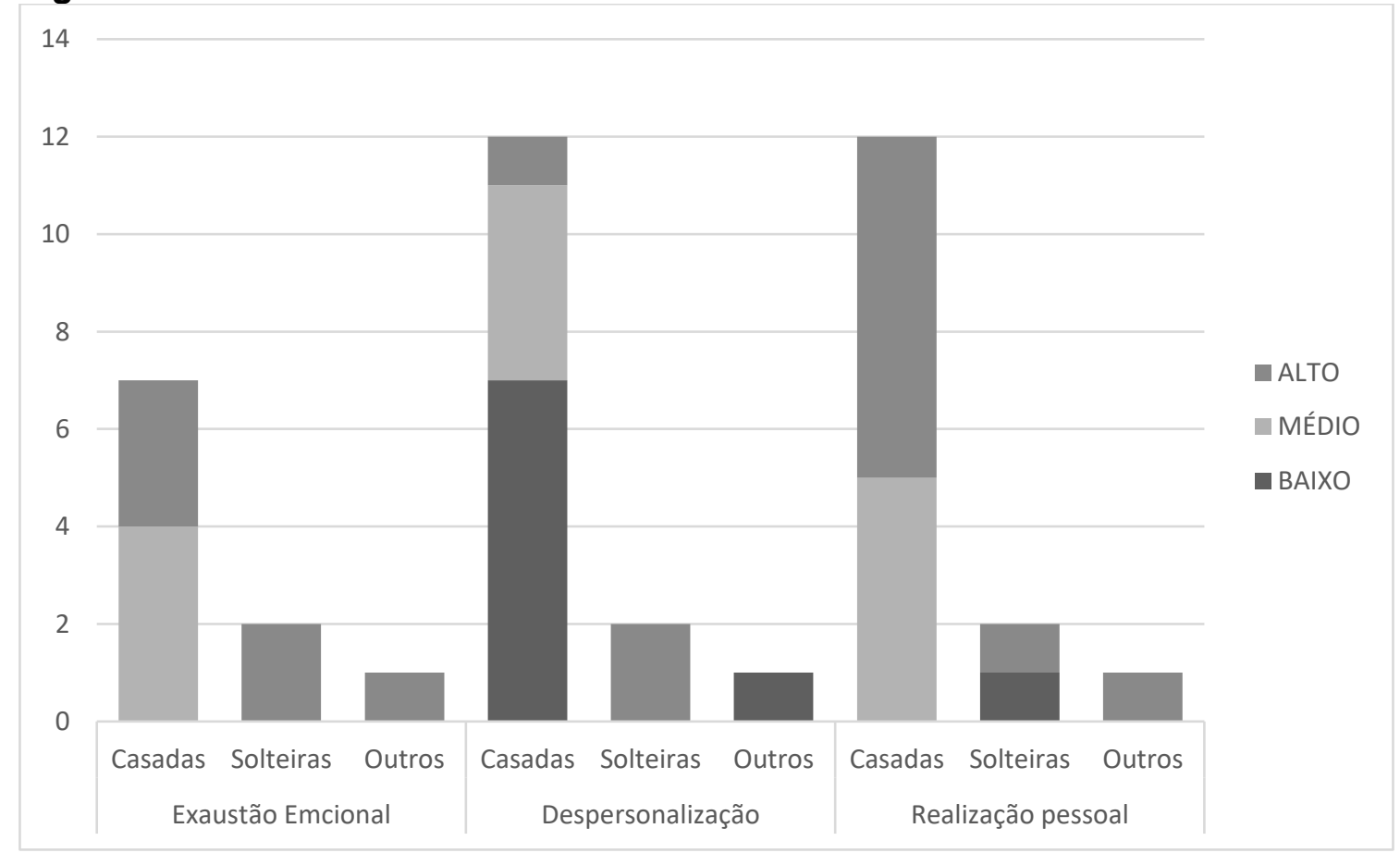

Fonte: Resultados originais da pesquisa

Quanto à variável idade, as participantes mais jovens, com até 39 anos, foram as que apresentaram maiores níveis de Burnout, sendo quatro delas $(n=4)$ com elevada EE, duas ( $n=2)$, alta DE e uma $(n=1)$ manifestava baixa RP (Figura 
9). De acordo com estudos, apesar de a idade não ser um fator definitivo para o Burnout, os professores com menos de 40 anos têm maior probabilidade de desenvolver a síndrome, pois, geralmente, ainda não possuem maturidade e experiência no trato com as problemáticas do cotidiano no trabalho. Além disso, alimentam expectativas acerca da carreira profissional, as quais muitas vezes não condizem com a realidade (SILVA, 2014; SPITLLE et al, 2015).

Esses resultados apontam, assim como nos estudos de Sinott (2013), que indivíduos com idade mais avançada apresentam menor exaustão emocional, pois, em geral, à medida que os anos avançam, o profissional, como no caso dos professores, vai ganhando maior segurança nas atividades e, consequentemente, menor vulnerabilidade às tensões laborais. Ainda assim, um estudo feito por Brouwers et al (2011) com professores na Holanda afirma que a idade é uma variável que precisa ser mais investigada, uma vez que os docentes podem apresentar mais queixas físicas e se sintam mais limitados à medida que envelhecem, podendo comprometer suas atividades laborais.

Figura 9: Variável Idade e dimensões do Burnout

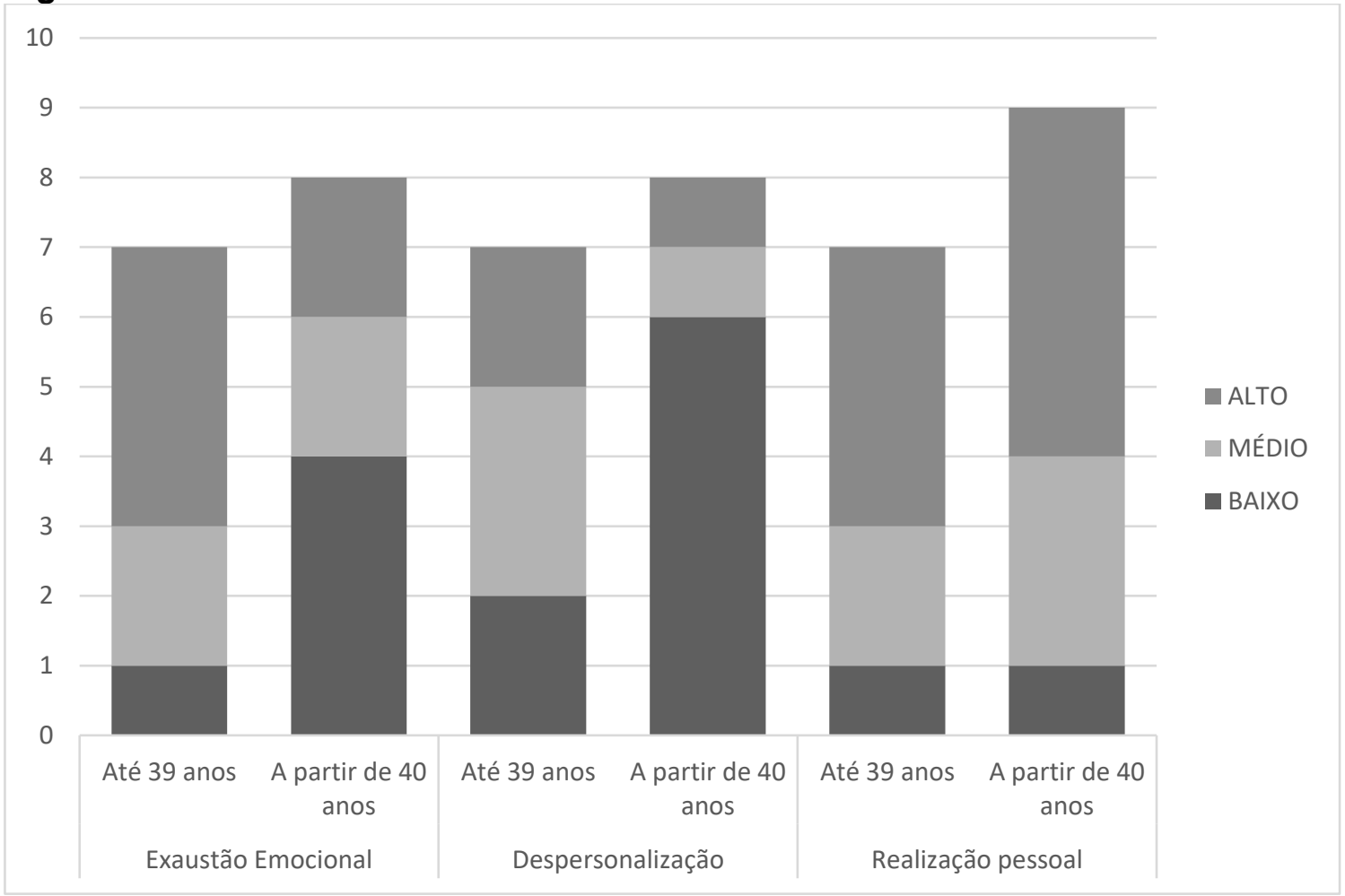

Fonte: Resultados originais da pesquisa

Os resultados quanto à variável tempo de exercício na função, Figura 10, indicam que as participantes que trabalham de 6 a 10 anos na função são as que 
têm maior nível de EE. As que trabalham há mais de 10 anos tiveram maior $\mathrm{DE}$, que pode ser considerada como uma estratégia defensiva para lidar com os conflitos no trato com as pessoas que são usuárias do serviço ou os colegas de trabalho. Já entre as que trabalhavam de 1 a 5 anos, foram encontrados maiores níveis de baixa RP. Esses achados se relacionam com a pesquisa nacional feita por Codo (1999), em que as análises demostraram que o Burnout vai avançando com o passar dos anos no trabalho, apresentando índices elevados da síndrome já nos primeiros cinco anos de profissão, atingindo o ápice nos trabalhadores da educação entre os 10 e 15 anos de atuação e, depois, diminuindo, quanto maior o tempo de exercício na função.

Figura 10: Variável Tempo de exercício na função e dimensões do Burnout

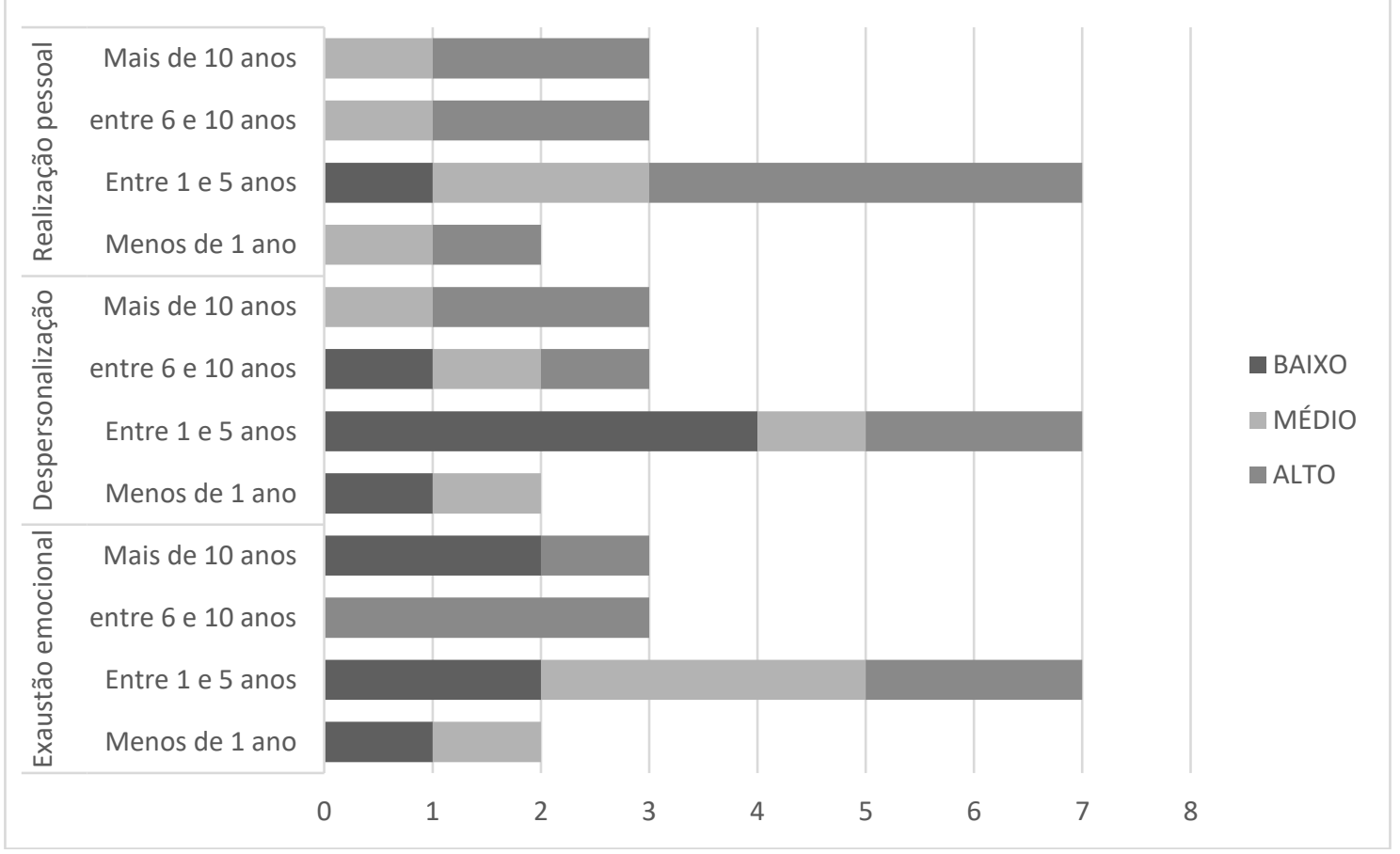

Fonte: Resultados originais da pesquisa

Em relação à carga horária de trabalho, uma $(n=1)$ participante apresentou alto nível de EE e DE e reduzida RP, simultaneamente. Entre as que trabalham mais de 40 horas por semana, a dimensão com maiores índices foi a $E E$, com quatro $(n=4)$. É interessante observar que, apesar disso, nesse mesmo grupo, em oito $(n=8)$ das entrevistadas, houve baixo índice de DE e nove $(n=9)$ estão realizadas pessoalmente no trabalho (Figura 11). 
Figura 11: Variável carga horária de trabalho e dimensões do Burnout

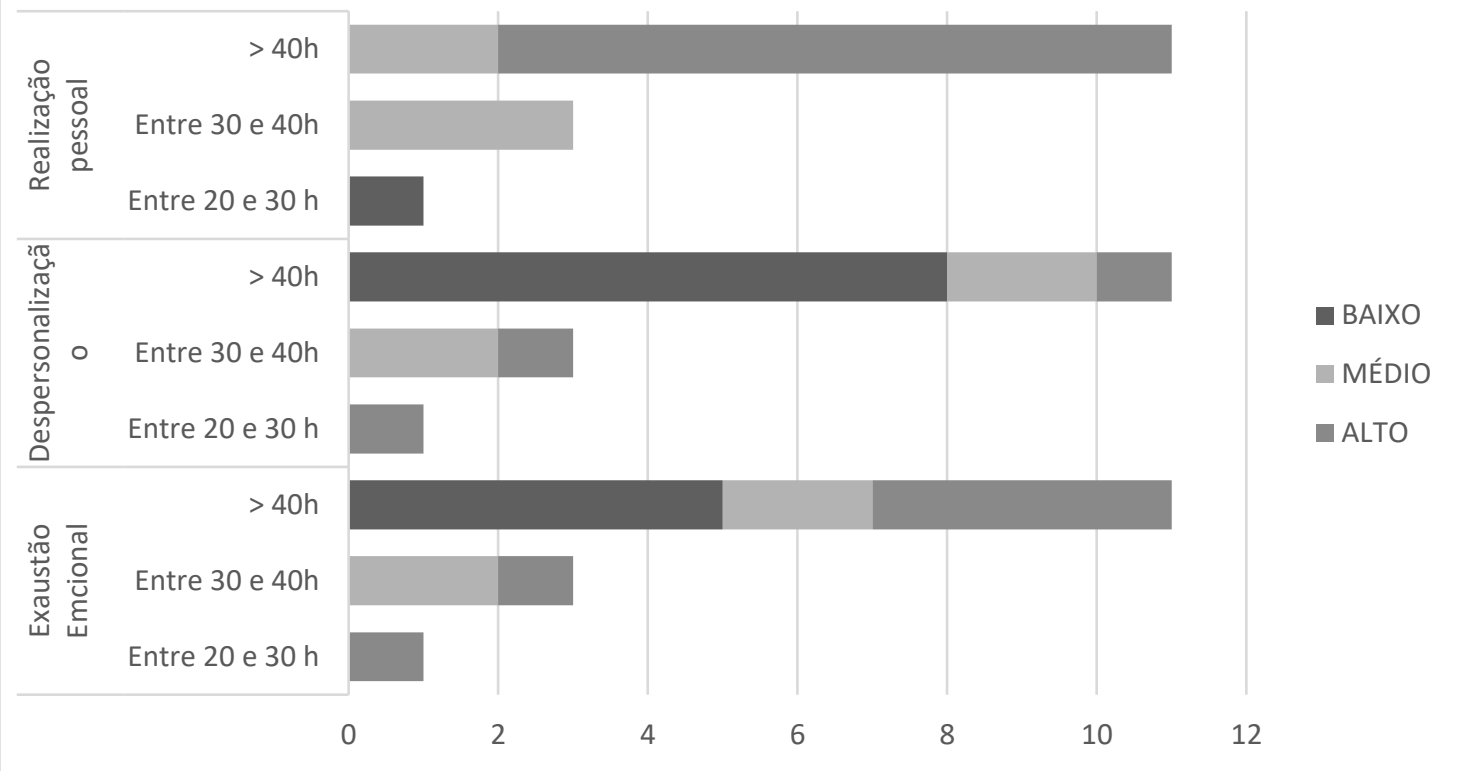

Fonte: Resultados originais da pesquisa

Na Figura 12, verifica-se que, em relação à variável nível de ensino, os maiores índices de Burnout estão entre as participantes que atuam no ensino fundamental e ensino médio simultaneamente, bem como com as que atuam em todos os níveis, em sua maioria, as diretoras das escolas. Esse resultado pode estar relacionado as mais variadas demandas que esse nível exige, tais como: lidar um maior número de professores de diversas disciplinas, por consequência, a organização de mais avaliações, maiores cobranças com relação a resultados de avaliações externas e a faixa etária dos alunos, que, geralmente, passam por diversos conflitos no contexto escolar, familiar e afetivo nesse período da vida. 
Figura 12: Variável nível de ensino em que atua e dimensões do Burnout

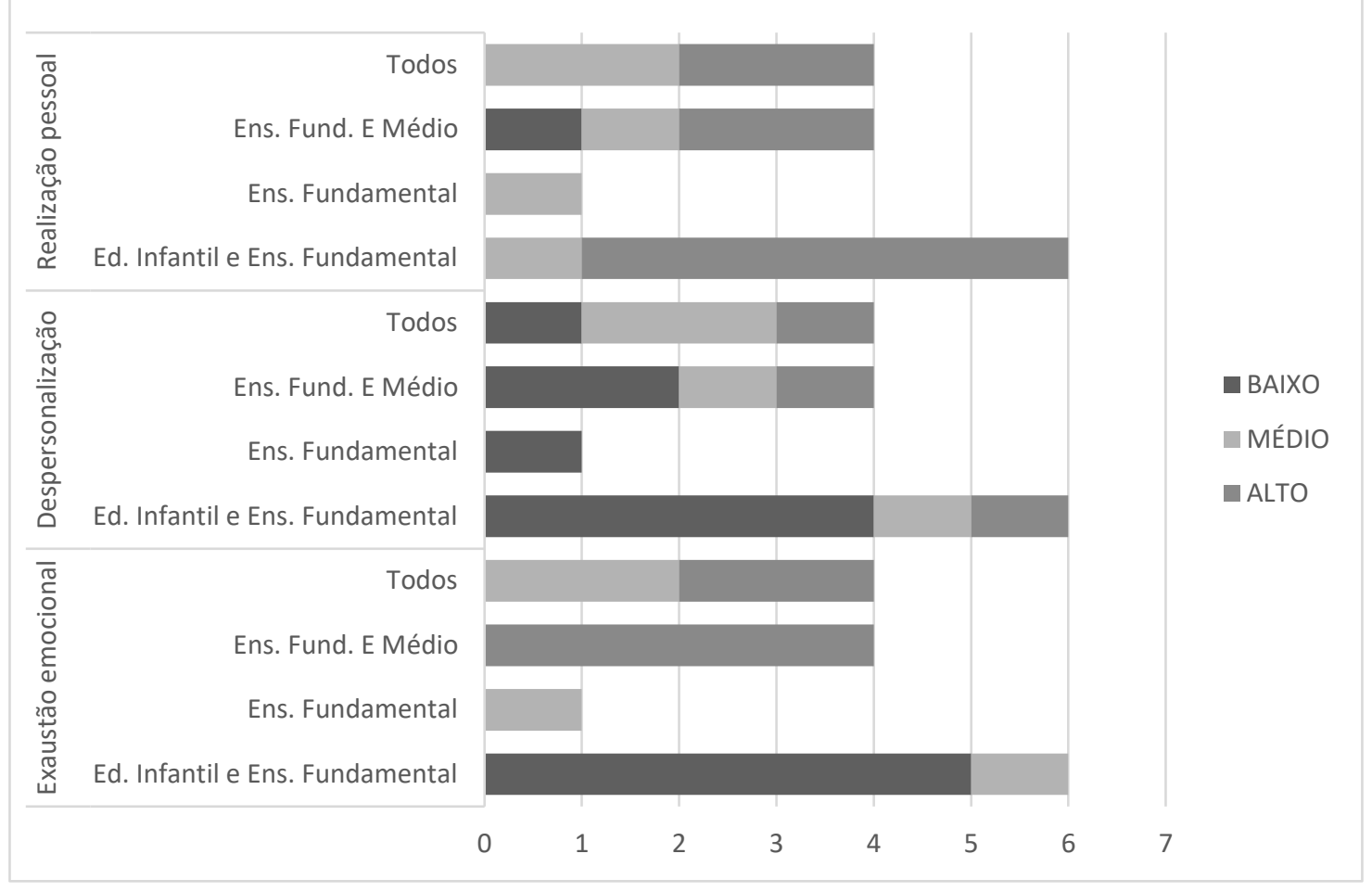

Fonte: Resultados originais da pesquisa

\subsection{Sentimentos negativos em relação ao trabalho}

As participantes deste estudo também foram indagadas sobre quais seriam as principais fontes de seus sentimentos negativos relacionados à sua atuação no trabalho. As opções eram: lidar com alunos, lidar com os professores, lidar com pais e/ou responsáveis, lidar com funcionários, lidar com questões burocráticas (avaliações, metas, documentos etc.) ou outros. As entrevistadas poderiam marcar mais de uma opção, se assim desejassem. A figura 13 expressa esses sentimentos por função exercida pelas participantes. 
Figura 13: Fontes de sentimentos negativos em relação ao trabalho

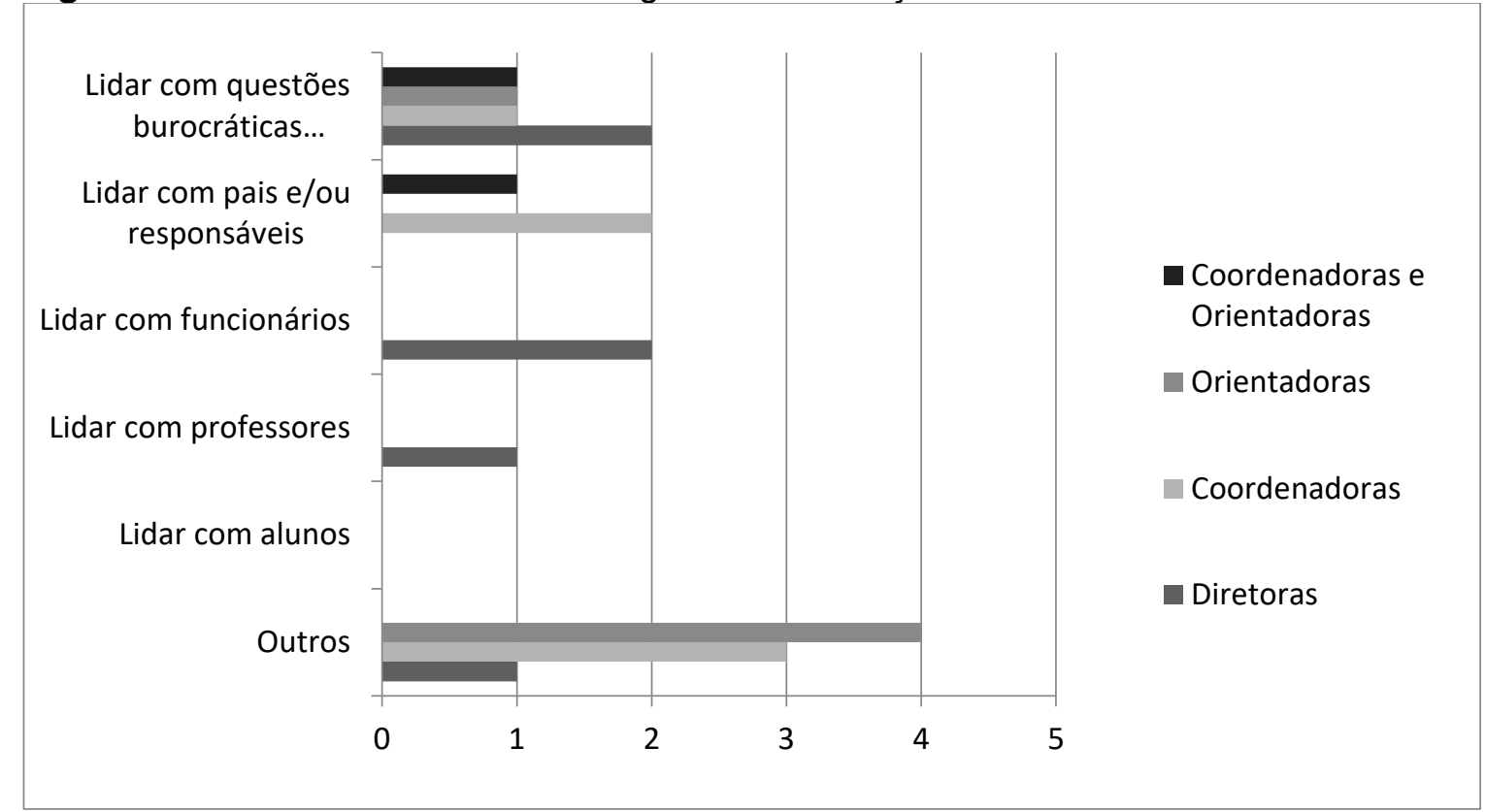

Fonte: Resultados originais da pesquisa

Constata-te que todos os cargos mencionaram a tarefa de ter que lidar com questões burocráticas como uma fonte de estresse no trabalho. Além dessa, nota-se que as diretoras indicaram as questões referentes ao trato com funcionários e professores, não mencionando, por sua vez, dificuldades com relação aos pais dos alunos, usuários indiretos dos serviços prestados pela escola e que, geralmente, por se tratar de uma instituição privada, apresentam maiores exigências à administração escolar. Outro fator interessante é que nenhuma das participantes relatou ter problemas com os alunos. Percebe-se, todavia, a necessidade de investigar quais seriam os problemas indicados na opção "Outros", que foi a mais escolhida por $53,3 \%(n=8)$ da amostra.

\section{Considerações finais}

Conclui-se que a maioria das participantes apresentou alta exaustão emocional, baixa despersonalização e moderado nível de realização pessoal no trabalho, evidenciando que a síndrome pode estar em desenvolvimento no grupo investigado. Uma das entrevistadas apresentou alta EE, alta DE e baixa RP simultaneamente. Com relação às características sociodemográficas, as participantes mais jovens e solteiras apresentaram maiores índices da síndrome. Já nas características do trabalho, as profissionais que trabalham de 1 a 5 anos tiveram menos RP, enquanto as que já atuam de 6 a 10 anos possuíram maior 
EE e as que estão há mais de 10 anos têm mais DE. A maior parte das entrevistadas trabalha mais de 40 horas por semana, estando predispostas a maior EE. Além disso, as que lidam com o nível de ensino fundamental e médio, ao mesmo tempo, tiveram índices alterados em todas as dimensões do Burnout.

Pensar a educação é refletir sobre o papel de todos os atores que fazem parte do da escola e a sua influência nas relações de ensino e aprendizagem, no clima organizacional e, consequentemente, na qualidade dos serviços educacionais prestados à comunidade escolar. Porém, uma vez que os profissionais que lidam com a organização e gestão escolar se encontram esgotados emocionalmente, por conta das inúmeras demandas estressoras no ambiente laboral, a tendência é que os sintomas manifestados pela síndrome prejudiquem tanto a vida quanto o trabalho do sujeito, influenciando também as relações interpessoais que acontecem no ambiente escolar com professores, funcionários, pais e alunos.

Por isso, este estudo visa a contribuir para que futuras pesquisas possam surgir a partir das lacunas e dos resultados encontrados. Mostra sua relevância, a partir do momento em que constata que o Burnout está presente nesse setor de atuação e percebe ser necessário o apoio e atenção psicológica à equipe de gestão escolar como um todo, para que exerçam suas funções com saúde e qualidade, prevenindo e tratando os sintomas da Síndrome de Burnout.

\section{Referências bibliográficas}

BARROS, S.; EUGÊNIO, B. G. O coordenador pedagógico na escola: formação, trabalho, dilemas. Educação, Gestão e Sociedade: Revista da Faculdade Eça de Queirós, Ano 4, n. 16, p.1-15, nov 2014.

BENEVIDES-PEREIRA, A. M. T. MBI - Maslach Burnout Inventory e suas adaptações para o Brasil. In: REUNIÃO ANUAL DE PSICOLOGIA. 22., Rio de Janeiro, 2001. Anais... Rio de Janeiro: s/e, 2001. p. 84-85.

BENEVIDES-PEREIRA, A.M.T. et al. O trabalho docente e o burnout: um estudo com professores paranaenses. In: CONGRESSO NACIONAL DE EDUCAÇÃO - EDUCERE. 8., Curitiba, 2008. Anais... Curitiba: s/e, 2008. p. 4870-4884.

BRASIL. Ministério da Saúde do Brasil - Doenças relacionadas ao trabalho: manual de procedimentos para os serviços de saúde. Brasília: Ministério da Saúde, 2001. (Série A. Normas e Manuais Técnicos, n. 114). p.580. 
BROUWERS, A.; TOMIC, W.; BOLUIJT, H. Job demands, job control, social support and self-efficacy beliefs as determinants of burnout among physical education teachers. Europe's Journal of Psychology, v. 7, n. 1, p. 17-39, 2011.

CARLOTTO, M. S. A Síndrome de Burnout e o trabalho docente. Psicologia em Estudo, v. 7, n. 1, p. 21-29, 2002.

CODO, W. Educação: carinho e trabalho. 4⿳a ed. Petrópolis-RJ: Vozes, 1999.

CODO, W.; VASQUEZ-MENEZES, I. O que é burnout? IN: Codo, W.

(Coord.). Educação: carinho e trabalho. $4^{\mathrm{a}}$ ed. Petrópolis-RJ: Vozes, 1999. p. 237-254.

GARCIA, L. P. BENEVIDES-PEREIRA, A.M.T. Investigando o Burnout em professores universitários. Revista Eletrônica Interação Psy, v. 1, n. 1, p. 76-89, 2003.

GUIMARÃES, A.L.C.O. O estresse ocupacional do gestor escolar: um estudo nas escolas municipais do Cabula - Salvador - Bahia. Dissertação. (Mestrado Profissional em Gestão e Tecnologias Aplicadas à Educação) - Departamento de Educação, Universidade do Estado da Bahia, Salvador- BA, 2013.

LÜCK, H. Dimensões de gestão escolar e suas competências. Curitiba: Positivo, 2009.

MASLACH C.; GOLDBERG J. Prevention of Burnout: new perspectives. App/ Prev Psychol, v. 7, n. 1, p. 63-74, 1998.

MASLACH, C.; JACKSON, S. E. The measurement of experienced burnout. Journal of Occupational Behavior, v. 2, p. 99-113,1981.

MASLACH,C.; SHAUFELI, W.B.; LEITER, M.P. Job Burnout. Annu. Rev. Psychol, v. 52, p. 397-422, 2001.

MAZON, C.C.X. LEITE, L.P. O mal-estar docente em gestores escolares. Arquivos Brasileiros de Psicologia, v. 65, n. 2, p. 304-318, 2013.

MELO, L. O. "Escola é um campo minado": o trabalho de gestores do ensino médio da rede estadual do Acre e os efeitos subjetivos na saúde mental. Dissertação. (Mestrado em Psicologia) - Universidade Federal de Rondônia, Porto Velho, 2015.

OLIVEIRA, D.; VIEIRA, L. Condições de trabalho docente: uma análise a partir de sete estados brasileiros. In: Trabalho na educação básica: a condição docente em sete estados brasileiros. Belo horizonte: Fino Traço, 2012. p. 153-190.

PASE NETO, M. J.; SANTOS, L. F. O orientador educacional na escola: papel, importância, atribuições e desafios. ÁGORA Revista Eletrônica, ano X, v. 20, p. 77-92, 2015.

PÊGO, F.P.L.; PÊGO; D.R. Síndrome de Burnout. Rev. Bras. Med. Trab, v. 14, n. 2, p. 171-176, 2016.

PIRES, D. A.; MONTEIRO, P. A. P.; ALENCAR, D. R. Síndrome de Burnout em professores de educação física da região nordeste do Pará. Pensar a Prática, v. 15, n. 4, p. 821-1113, 2012. 
PLACCO, V. M. N. S.; ALMEIDA, L. R. (Orgs.). O coordenador pedagógico e o cotidiano da escola. 5a ed. São Paulo: Edições Loyola, 2008.

ROBALINO, M. A saúde e o trabalho docente: um desafio para as políticas públicas da educação. In: OLIVEIRA, D.; VIEIRA; L. Trabalho na educação básica: a condição docente em sete estados brasileiros. Belo horizonte: Fino Traço, 2012. p. 71-397.

SILVA, G. M. Síndrome de Burnout em professores de educação física da rede pública estadual de Sergipe. Dissertação. (Mestrado em Educação Física) Universidade Federal de Sergipe, São Cristóvão, 2014.

SINOTT, E. C. Síndrome de Burnout: um estudo com professores de educação física das escolas municipais de Pelotas. 2013. Dissertação. (Mestrado em Educação Física) - Universidade Federal de Pelotas, Pelotas, 2013.

SPITTLE, M.; KREMER, P.; SULLIVAN, S. Burnout in secondary school physical education teaching. Physical Education and Sport, v.13, n. 1, p. 33-43, 2015. 